\title{
Soroprevalência de anticorpos anti-Toxoplasma gondii em bovinos e funcionários de matadouros da microrregião de Pato Branco, Paraná, Brasil
}

\author{
Seroprevalence of anti-Toxoplasma gondii antibodies in cattle and slaughterhouse workers in \\ the region of Pato Branco, Paraná, Brazil
}

\author{
Heitor Daguer ${ }^{1}$ Regiane Trigueiro Vicente ${ }^{2}$ Tatiana da Costa ${ }^{2}$ Maurício Paulo Virmond ${ }^{3}$ \\ Waldir Hamann ${ }^{4}$ Maria Regina Reis Amendoeira ${ }^{5}$
}

RESUMO

Visando avaliar a participação da carne bovina na epidemiologia da toxoplasmose, foram coletadas amostras de soro de 348 bovinos e de 64 funcionários em quatro matadouros da microrregião de Pato Branco, Estado do Paraná, Brasil. Os soros dos bovinos foram avaliados pela reação de imunofluorescência indireta (RIFI) e apresentaram soropositividade ( $\mathrm{Ig} G$ ) em 41,4\% das amostras examinadas. O título mais freqüentemente encontrado foi o de 64 (92,4\%). Nenhum animal apresentou título superior a 1024. Não foram encontradas diferenças significativas em relação ao sexo, idade e procedência dos animais. Os soros humanos, avaliados pelos testes de RIFI e de ELISA (imunoensaio enzimático) para $\operatorname{Ig} G$, apresentaram $67,2 \%$ e $84,4 \%$ de positividade, respectivamente. Não foram encontradas diferenças significativas com relação às variáveis idade, sexo, tempo de serviço no abatedouro, contato com gatos $e$ hábito de ingerir carne crua ou mal cozida. Os resultados sugerem que a carne bovina pode desempenhar importante papel na manutenção da toxoplasmose na região.

Palavras-chave: toxoplasmose; bovinos; matadouros; anticorpos.

\section{ABSTRACT}

In order to determine the role of bovine meat in the epidemiology of toxoplasmosis, 348 serum samples were collected from cattle and 64 serum samples from slaughterhouse workers at four plants in the region of Pato Branco, Paraná state, southern Brazil. Cattle sera were examined by the indirect fluorescent antibody test (IFAT), showing an IgG-seropositivity of $41.4 \%$.
The most frequently titer found was 64 (92.4\%). Maximum titer found was 1024. There was no significant difference concerning sex, age and origin of positive sera. Human sera were tested by the IFAT and enzyme-linked immunosorbent assay (ELISA), showing $67.2 \%$ and $84.4 \%$ of IgG-seropositivity, respectively. No significant difference was observed between prevalences and age, sex, duration of employment at slaughterhouse, contact with cats and eating raw or undercooked meat. Results suggest that bovine meat may be a possible source of toxoplasmosis in the region.

Key words: toxoplasmosis; cattle; slaughterhouses; antibodies.

\section{INTRODUÇÃO}

A toxoplasmose é uma zoonose de distribuição mundial que acomete o homem e outros animais de sangue quente (mamíferos e aves), tanto de produção quanto de companhia, domésticos e silvestres, sendo causada pelo protozoário Toxoplasma gondii, única espécie existente no gênero. Os felídeos, principalmente os gatos, desempenham papel fundamental na transmissão do T. gondii para o homem e outros animais, pois são os únicos hospedeiros que eliminam oocistos do parasita pelas fezes. Os oocistos são resistentes às condições ambientais e resultam da fase sexuada do ciclo, que é limitada ao epitélio intestinal desses animais (DUBEY, 1995).

\footnotetext{
${ }^{1}$ Médico Veterinário, MSc, Ministério da Agricultura, Pecuária e Abastecimento, Serviço de Inspeção Federal, Rua Ubirajara Araújo, 760, Palmas, PR, 85555-000, Brasil. E-mail: daguer@proserv.com.br. Autor para correspondência.

${ }^{2}$ Biólogo, Bolsista do Instituto Oswaldo Cruz, Rio de Janeiro, RJ, Brasil.

${ }^{3}$ Médico Veterinário, Centro de Diagnóstico Virmond, Francisco Beltrão, PR, Brasil.

${ }^{4}$ Médico Veterinário, Dr, Professor da Universidade Federal do Paraná, Setor de Ciências Agrárias, Departamento de Medicina Veterinária, Curitiba, PR, Brasil.

${ }_{5}^{5}$ Biólogo, Dr, Pesquisador do Laboratório de Toxoplasmose, Departamento de Protozoologia, Instituto Oswaldo Cruz, Rio de Janeiro, RJ, Brasil.
} 
Os demais animais mantêm apenas a fase assexuada do ciclo e desempenham o papel de hospedeiros intermediários, transmitindo a infecção somente quando sua carne é consumida crua ou mal cozida ou por via congênita. Formas viáveis do $\boldsymbol{T}$. gondii têm sido isoladas de grande variedade de carnes e estudos sorológicos têm evidenciado ampla distribuição da infecção entre os animais produtores desse alimento (ARIAS et al., 1994).

Apesar de os bovinos constarem entre os hospedeiros mais resistentes ao $\boldsymbol{T}$. gondii, o papel da carne bovina na transmissão da toxoplasmose permanece obscuro e são necessárias pesquisas para a determinação de animais infectados dentre os bovinos abatidos (DUBEY \& THULLIEZ, 1993; HORIO et al., 2001). O objetivo do presente trabalho foi estimar a freqüência de soro-reagentes ao $\boldsymbol{T}$. gondii em bovinos abatidos para consumo humano e em funcionários de matadouros da microrregião de Pato Branco, visando contribuir para o estudo da cadeia epidemiológica da toxoplasmose naquela microrregião.

\section{MATERIAL E MÉTODOS}

A microrregião de Pato Branco corresponde à porção leste da região sudoeste do Estado do Paraná (sul do Brasil), com clima subtropical úmido mesotérmico, sendo a temperatura média nos meses mais quentes superior a $22^{\circ} \mathrm{C}$ e inferior a $18^{\circ} \mathrm{C}$ nos meses mais frios (IPARDES, 2002). Contígua à microrregião de Pato Branco situa-se a microrregião de Francisco Beltrão, correspondendo à porção oeste da região sudoeste do Paraná.

Foram colhidas amostras de soros de 348 bovinos (261 machos e 87 fêmeas) abatidos nos quatro matadouros sob Inspeção Estadual da microrregião, entre abril de 2001 e março de 2002. Os animais eram provenientes de 14 municípios da região sudoeste do estado e não se fez distinção de raça na população estudada. A amostragem populacional foi obtida utilizando-se o programa Epi-Info versão 6, com expectativa de prevalência de $30 \%$, obtendo-se uma amostra epidemiologicamente significativa. Foram também colhidas amostras de soros de 64 funcionários (60 homens e 4 mulheres) desses matadouros, entre magarefes, médicos veterinários e técnicos de inspeção sanitária. Paralelamente à coleta, os funcionários respondiam a um questionário epidemiológico.

As análises sorológicas foram realizadas no Instituto Oswaldo Cruz, no Rio de Janeiro. Os soros dos bovinos foram examinados para detecção de anticorpos da classe IgG, específicos para T. gondii, através da reação de imunofluorescência indireta (RIFI), conforme técnica descrita por CAMARGO (1964). Os soros humanos foram examinados para detecção de anticorpos anti-T. gondii das classes IgG e IgM pela RIFI (CAMARGO, 1964) e para anticorpos anti-T. gondii da classe IgG por meio da técnica de imunoensaio enzimático (ELISA), conforme técnica descrita por VOLLER et al. (1976).

$\mathrm{O}$ antígeno utilizado foi obtido de exsudato peritonial de camundongos Swiss Webster (Mus musculus), infectados com taquizoítas da cepa RH de $\boldsymbol{T}$. gondii. Nas análises sorológicas utilizaram-se conjugados específicos para a espécie em exame e para a técnica desenvolvida. Os soros dos bovinos foram diluídos a 1:64, 1:256, 1:1024 e 1:4096 para a leitura da RIFI, sendo a positividade considerada como maior ou igual a 1:64. Os soros humanos foram diluídos a $1: 16,1: 64,1: 256,1: 1024$ e 1:4096 para a RIFI, sendo considerados positivos aqueles com títulos de anticorpos iguais ou superiores a 16. Em todas as leituras, foram acrescentados controles positivos e negativos e um controle do conjugado a cada lâmina. No ELISA, foram considerados positivos os soros que apresentaram leituras iguais ou superiores ao valor de cut off da placa, sendo que em cada placa foram utilizados dois soros negativos e um positivo para controle. $\mathrm{O}$ cut off de cada placa foi obtido a partir das médias das leituras dos soros negativos, adicionadas de dois desvios-padrão.

Nas análises estatísticas, foram utilizados o teste do qui-quadrado $\left(\mathrm{c}^{2}\right)$ e o teste exato de Fisher, utilizando-se o nível de significância de 5\%. Para avaliar a concordância real entre as técnicas sorológicas utilizadas em humanos, foi calculado o índice de concordância ajustada kappa $(\mathrm{k})$.

\section{RESULTADOS E DISCUSSÃO}

A prevalência sorológica de bovinos reagentes para toxoplasmose é bem conhecida no norte do Estado do Paraná, onde GARCIA et al. (1999a) encontraram $25,8 \%$ de positivos para anticorpos IgG. Na mesma região, MARANA et al. (1994) detectaram soroprevalência de 32,3\% em animais abatidos em matadouros. A prevalência encontrada na presente pesquisa $(41,4 \%)$ foi mais elevada que a dos referidos autores. Em 1995, MARANA et al. detectaram 48,5\% de reagentes em rebanhos de leite, também do norte paranaense, resultado concordante com o presente. Todos os autores referidos empregaram a RIFI como técnica sorológica.

Encontrou-se uma positividade de $42,9 \% \mathrm{e}$ $36,8 \%$ entre machos e fêmeas, respectivamente, não 
sendo a diferença considerada estatisticamente significativa ( $p=0,379)$, o que também tem sido observado na literatura (ARIAS et al., 1994; GARCIA et al., 1999a). Na tabela 1, estão relacionados os resultados dos bovinos reagentes agrupados por idade e pelo maior título de anticorpos encontrado. Embora se tenha verificado menor soropositividade nos bovinos adultos $(40,5 \%)$ em relação aos animais com menos de um ano $(46,8 \%)$, esta variação não foi significativa $(p=0,887)$, fato também observado por GARCIA et al. (1999a). Os baixos títulos encontrados corroboram os achados de MARANA et al. (1994), que também encontraram títulos máximos de 1024 em bovinos. De acordo com GARCIA et al. (1999a), baixos títulos de anticorpos são sugestivos de infecções crônicas, com presença de cistos teciduais.

Observou-se uma variação não significativa ( $p=1,324)$ de $36,5 \%$ a $43,3 \%$ na freqüência de reagentes entre os bovinos procedentes das microrregiões de Francisco Beltrão e Pato Branco, respectivamente. As duas microrregiões possuem características geográficas muito semelhantes, o que deve justificar o observado.

No Brasil, tem se demonstrado que, em humanos adultos, a prevalência de reagentes para anticorpos anti-T. gondii varia de $40 \%$ a $80 \%$ (CANTOS et al., 2000). Na presente pesquisa, observou-se uma variação de $70 \%$ a $90,9 \%$ de sororeagentes entre os funcionários dos quatro matadouros quando se analisaram os resultados positivos nas técnicas de ELISA e/ou RIFI (Tabela 2), não sendo, contudo, considerada significativa $(p=1,320)$. Na população estudada, a positividade foi de $67,2 \%$ e
84,4\%, por meio das técnicas de RIFI e ELISA, respectivamente, obtendo-se índice de concordância regular entre as duas técnicas $(\mathrm{k}=0,55)$. A prevalência encontrada é mais baixa que a revelada pelos trabalhos de ISHIZUKA (1978), que detectou 97,1\% de positividade para anticorpos anti-T. gondii em magarefes de São Paulo. No entanto, é concordante com os achados de SOUZA (1995), que encontrou $84,7 \%$ de magarefes reagentes abatedouros do Rio de Janeiro.

Os percentuais de indivíduos $\mathrm{IgG}$ reagentes segundo sexo, faixa etária, tempo de serviço no matadouro, contato com gatos e hábito de ingerir carne crua ou mal cozida estão expostos na tabela 3 . Indivíduos de ambos os sexos desenvolviam atividades de manipulação de carcaças e vísceras nos abatedouros, não sendo observadas diferenças significantes entre os sexos $(p=0,502)$, o que corrobora os achados de HORIO et al. (2001). Observa-se um aumento proporcional da frequiência de soro-reagentes nas faixas etárias mais elevadas, sem haver, no entanto, diferença significante em relação à distribuição por faixa etária $(p=0,316)$, corroborando os achados de GARCIA et al. (1999b). O tempo de serviço não influenciou estatisticamente na distribuição dos soro-reagentes entre os funcionários ( $p=0,409)$, o que não está de acordo com HORIO et al. (2001), que encontraram considerável diferença de soro-reagentes entre os indivíduos com menos de cinco anos $(25 \%)$ e os com mais de seis anos $(41,5 \%)$ de atividades no matadouro.

A positividade foi maior entre os indivíduos que não possuíam gatos $(90 \%)$ do que entre os que

Tabela 1 - Distribuição dos soros reagentes à reação de imunofluorescência indireta (RIFI), para pesquisa de anticorpos anti-T. gondii da classe IgG, de acordo com a faixa etária e a maior diluição encontrada, em bovinos abatidos nos matadouros sob Inspeção Estadual da microrregião de Pato Branco, Paraná, Brasil, 2002.

\begin{tabular}{|c|c|c|c|c|c|}
\hline Idade (anos) & $\begin{array}{l}\text { Não } \\
\text { reagentes }\end{array}$ & $1: 64$ & $1: 256$ & $1: 1024$ & Total \\
\hline \multirow{2}{*}{$<1$} & $7,2 \%$ & $6,0 \%$ & $0,3 \%$ & $0 \%$ & $13,5 \%$ \\
\hline & (25) & (21) & (1) & (0) & (47) \\
\hline \multirow{2}{*}{$1,1-2$} & $13,8 \%$ & $7,5 \%$ & $1,2 \%$ & $0,6 \%$ & $23,0 \%$ \\
\hline & (48) & (26) & (4) & (2) & $(80)$ \\
\hline \multirow{2}{*}{$2,1-3$} & $16,4 \%$ & $9,5 \%$ & $0 \%$ & $0,6 \%$ & $26,4 \%$ \\
\hline & (57) & (33) & (0) & (2) & $(92)$ \\
\hline \multirow{2}{*}{$3,1-4$} & $10,9 \%$ & $8,0 \%$ & $0 \%$ & $0 \%$ & $19,0 \%$ \\
\hline & (38) & (28) & (0) & (0) & (66) \\
\hline \multirow{2}{*}{$>4$} & $10,3 \%$ & $7,2 \%$ & $0,5 \%$ & $0 \%$ & $18,1 \%$ \\
\hline & (36) & (25) & (2) & (0) & (63) \\
\hline \multirow{2}{*}{ Total } & $58,6 \%$ & $38,2 \%$ & $2,0 \%$ & $1,2 \%$ & $100,0 \%$ \\
\hline & (204) & (133) & (7) & (4) & $(348)$ \\
\hline
\end{tabular}

Entre parênteses o número total de animais de cada grupo.

Ciência Rural, v.34, n.4, jul-ago, 2004. 
Tabela 2 - Distribuição dos soros reagentes às técnicas de reação de imunofluorescência indireta (RIFI) e/ou imunoensaio enzimático (ELISA) para a pesquisa de anticorpos da classe IgG anti-T. gondii em funcionários de matadouros de bovinos sob Inspeção Estadual da microrregião de Pato Branco, Paraná, Brasil, 2002, de acordo com o estabelecimento.

\begin{tabular}{lcccccc}
\hline \multirow{2}{*}{ Matadouro } & \multicolumn{2}{c}{ Reagentes } & \multicolumn{2}{c}{ Não reagentes } & \multicolumn{2}{c}{ Total de soros examinados } \\
& $\mathrm{n}$ & $\%$ & $\mathrm{n}$ & $\%$ & $\mathrm{n}$ & $\%$ \\
\hline SIP 21 & 20 & 90,9 & 02 & 9,1 & 22 & 34,4 \\
SIP 43 & 13 & 81,3 & 03 & 18,7 & 16 & 25,0 \\
SIP 50 & 14 & 87,5 & 02 & 12,5 & 16 & 25,0 \\
SIP 94 & 07 & 70,0 & 03 & 30,0 & 10 & 15,6 \\
\hline Total & 54 & 84,4 & 10 & 15,6 & 64 & 100,0 \\
\hline
\end{tabular}

possuíam contato com esses animais $(75 \%)$, embora esta diferença não tenha sido considerada estatisticamente significativa $(p=0,157)$. HORIO et al. (2001) também encontraram maior positividade entre magarefes não proprietários de gatos $(41,7 \%)$ do que entre proprietários desses animais (10,5\%), sugerindo que gatos não seriam a principal fonte de infecção para estes trabalhadores, mas sim os animais abatidos.

Alguns autores atribuem grande importância do consumo de carne vermelha em relação ao aumento da infecção por $\boldsymbol{T}$. gondii em humanos (ARIAS et al., 1994). Na presente pesquisa, 84,1\% dos indivíduos que comiam carne crua ou mal cozida eram soro-reagentes, enquanto $85 \%$ dos que não comiam também apresentavam anticorpos específicos anti-T. gondii, o que sugere que a ingestão de cistos teciduais pelo consumo de carne crua ou mal cozida foi responsável pela infecção apenas de parte desses indivíduos $(p=1)$. Uma possível explicação para o achado reside no pouco conhecimento da quantidade de cistos teciduais existente na carne e vísceras dos animais de açougue (ESTEBAN-REDONDO et al., 1999). Porém, mesmo que a incidência de infecção da carne seja baixa, a freqüência e a forma como é consumida proporcionam o grau de exposição e risco à infecção toxoplásmica (FRENKEL \& DUBEY, 1972).

Observou-se que 95,3\% dos funcionários soro-reagentes apresentaram títulos inferiores a 64 e nenhum dos indivíduos examinados apresentou anticorpos IgM específicos anti-T. gondii, sugerindo a existência de infecção crônica. Estes dados corroboram os de SOUZA (1995), que também

Tabela 3 - Distribuição dos funcionários de matadouros da microrregião de Pato Branco, Paraná, Brasil, 2002, reagentes para anticorpos anti-T. gondii da classe IgG pelas técnicas de reação de imunofluorescência indireta (RIFI) e/ou imunoensaio enzimático (ELISA), de acordo com as variáveis sexo, faixa etária, tempo de serviço, contato com gatos e hábito de ingerir carne crua ou mal cozida.

\begin{tabular}{|c|c|c|c|}
\hline Variável & Reagentes & Não reagentes & Total \\
\hline \multicolumn{4}{|l|}{ Sexo } \\
\hline Masculino & $51(85,0 \%)$ & $9(15,0 \%)$ & 60 \\
\hline Feminino & $3(75,0 \%)$ & $1(25,0 \%)$ & 4 \\
\hline \multicolumn{4}{|l|}{ Faixa etária } \\
\hline$\leq 30$ & $13(76,5 \%)$ & $4(23,5 \%)$ & 17 \\
\hline $31-39$ & $18(81,8 \%)$ & $4(18,2 \%)$ & 22 \\
\hline$\geq 40$ & $23(92,0 \%)$ & $2(8,0 \%)$ & 25 \\
\hline \multicolumn{4}{|c|}{ Tempo de serviço } \\
\hline$\leq 5$ anos & $31(88,6 \%)$ & $4(11,4 \%)$ & 35 \\
\hline$\geq 6$ anos & $23(79,3 \%)$ & $6(20,7 \%)$ & 29 \\
\hline \multicolumn{4}{|c|}{ Contato com gatos } \\
\hline Sim & $18(75,0 \%)$ & $6(25,0 \%)$ & 24 \\
\hline Não & $36(90,0 \%)$ & $4(10,0 \%)$ & 40 \\
\hline \multicolumn{4}{|c|}{ Hábito de ingerir carne crua ou mal cozida } \\
\hline Sim & $37(84,1 \%)$ & $7(15,9 \%)$ & 44 \\
\hline Não & $17(85,0 \%)$ & $3(15,0 \%)$ & 20 \\
\hline
\end{tabular}


encontrou baixos títulos em magarefes.

$$
\text { DUBEY \& THULLIEZ }
$$

demonstraram que cistos teciduais podem permanecer viáveis por períodos superiores a três anos em corações, línguas e fígados de bovinos experimentalmente infectados. Esses achados demonstram a nítida existência de risco de infecção por $\boldsymbol{T}$. gondii pela manipulação não higiênica (principalmente para evisceradores e inspetores) ou mesmo pelo consumo dessas partes de forma crua ou mal cozida.

\section{CONCLUSÕES}

A alta prevalência de reagentes em bovinos e em funcionários de matadouros desses animais, revelada nesta pesquisa, sugere que esses bovinos possam servir de fonte de infecção para os consumidores que têm o hábito de consumir carne bovina crua ou mal cozida. Os manipuladores e os consumidores de carnes devem ser alertados quanto ao risco de infecção por $\boldsymbol{T}$. gondii por meio desse produto e orientados quanto à necessidade de adoção de medidas higiênicas e preventivas que visam minimizar a possibilidade de infecção desses indivíduos.

\section{AGRADECIMENTOS}

Os autores agradecem aos Profs. Dra. Roberta L. Freire e Dr. Italmar T. Navarro, da Universidade Estadual de Londrina (UEL), pelo conjugado para a RIFI dos bovinos e pelos soros-controle positivos e negativos.

\section{REFERÊNCIAS BIBLIOGRÁFICAS}

ARIAS, M.L. et al. Seroepidemiology of Toxoplasma gondii in meat producing animals in Costa Rica. Revista de Biología Tropical, San José, v.42, n.1/2, p.15-20, 1994.

CAMARGO, M.E. Improved technique of indirect immunofluorescence for serological diagnosis of toxoplasmosis. Revista do Instituto de Medicina Tropical de São Paulo, São Paulo, v.6, p.117-118, 1964.

CANTOS, G.A. et al. Toxoplasmose: ocorrência de anticorpos anti-Toxoplasma gondii e diagnóstico. Revista da Associação Médica Brasileira, São Paulo, v.46, n.4, p.335-341, 2000.

DUBEY, J.P. Duration of immunity to shedding of Toxoplasma gondii oocysts by cats. Journal of Parasitology, Lawrence, v.81, n.3, p.410-415, 1995.
DUBEY, J.P.; THULLIEZ, P. Persistence of tissue cysts in edible tissues of cattle fed Toxoplasma gondii oocysts. American Journal of Veterinary Research, Schaumburg, v.54, n.2, p.270273, 1993.

ESTEBAN-REDONDO, I. et al. Detection of $\boldsymbol{T}$. gondii in tissues of sheep and cattle following oral infection. Veterinary Parasitology, Amsterdam, v.86, p.155-171, 1999.

FRENKEL, J.K.; DUBEY, J.P. Toxoplasmosis and its prevention in cats and man. Journal of Infectious Diseases, Chicago, v.126, p.664-673, 1972.

GARCIA, J.L. et al. Soroprevalência do Toxoplasma gondii em suínos, bovinos, ovinos e eqüinos e sua correlação com humanos, felinos e caninos, oriundos de propriedades rurais do norte do Paraná, Brasil. Ciência Rural, Santa Maria, v.29, n.1, p.91-97, 1999a.

GARCIA, J.L. et al. Soroepidemiologia da toxoplasmose e avaliação ocular pela Tela de Amsler, em pacientes da zona rural, atendidos pela unidade de saúde do município de Jaguapitã, PR, Brasil. Revista da Sociedade Brasileira de Medicina Tropical, Uberaba, v.32, n.6, p.671-676, 1999 b.

HORIO, M.; NAKAMURA, K.; SHIMADA, M. Risk of Toxoplasma gondii infection in slaughterhouse workers in Kitakyushu City. Journal of University of Occupational and Environmental Health, Kitakyushu, v.23, n.3, p.233-243, 2001.

IPARDES - INSTITUTO PARANAENSE DEDESENVOLVIMENTO ECONÔMICO E SOCIAL. Base de dados. Capturado em 28 de dezembro de 2002. Online. Disponível na Internet: http:// www.pr.gov.br/ipardes

ISHIZUKA, M.M. Avaliação da freqüência de reagentes ao Toxoplasma gondii, pela prova de imunofluorescência indireta (anti-IgG), em magarefes. Revista da Faculdade de Medicina Veterinária e Zootecnia da Universidade de São Paulo, São Paulo, v.15, n.2, p.155-158, 1978.

MARANA, E.R.M. et al. Ocorrência de anticorpos antiToxoplasma gondii em bovinos de corte, abatidos em matadouros do norte do Paraná - Brasil. Semina, Londrina, v.15, n.1, p.3840, 1994.

MARANA, E.R.M. et al. Ocorrência de anticorpos antiToxoplasma gondii em rebanhos de bovinos de leite do norte do Paraná - Brasil. Semina, Londrina, v.16, n.1, p.40-42, 1995.

SOUZA, W.J.S. Epidemiologia da toxoplasmose: avaliação sorológica de suínos e trabalhadores em abatedouros na mesorregião do Grande Rio de Janeiro. 1995. 102f. Tese (Doutorado em Parasitologia Veterinária) - Curso de Pósgraduação em Medicina Veterinária, Universidade Federal Rural do Rio de Janeiro.

VOLLER, A.; BIDWELL, D. E.; BARTLETT, A. Enzyme immunoassays in diagnostic medicine. Bulletin of the World Health Organization, Geneve, v.53, n.1, p.55-65, 1976. 